The Place of Special

Collections in a Research

Library

Erin Mollenhauer

\title{
THE PLACE OF SPECIAL \\ COLLECTIONS IN A RESEARCH \\ LIBRARY
}

Erin Mollenhauer

Archivist and Special Collections Librarian

Moore Theological College, Sydney 


\section{The glamr sector}

- Galleries

- Libraries

- Archives

- Museums

- Records management

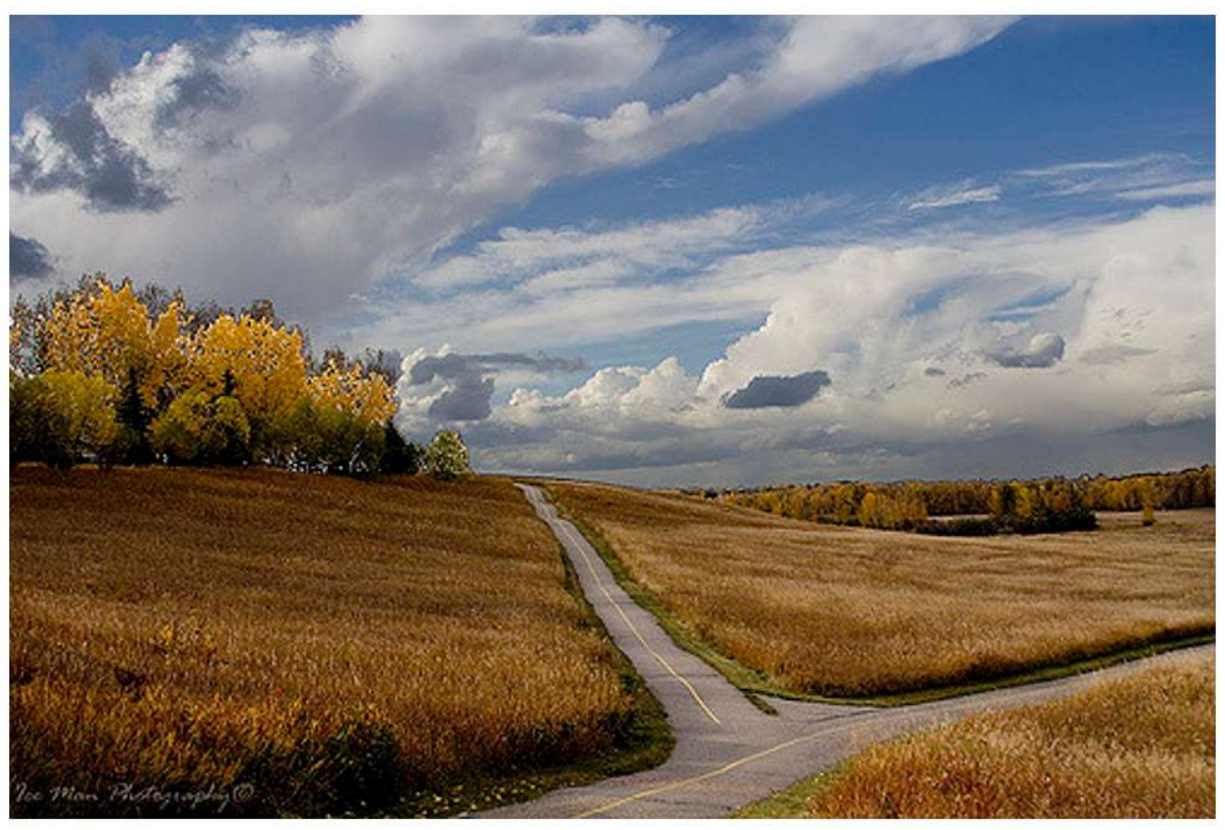




\section{Definitions}

- Research library = a library which collects and maintains in-depth material to support research in one or more subject areas

- Special collections = "collections of books and archives considered important enough to be preserved...they are rare, unique or fragile, they have research or cultural value, or significant provenance"

- University of Glasgow https://www.gla.ac.uk/myglasgow/specialcollections/whatarespecialcollections/

\section{Special collections}

- Manuscripts and personal archives

- Rare books

- Ephemera

- Original audio/visual material

- Realia

- Photographs

- Artworks 


\section{Significance}

"'Significance' refers to the values and meanings that items and collections have for people and communities. Significance helps unlock the potential of collections, creating opportunities for communities to access and enjoy collections, and to understand the history, cultures and environments of Australia"

Kylie Winkworth and Roslyn Russell. Significance 2.0: a guide to assessing the significance of collections. Collections Council of Australia, 2009. p.1.

\section{Types of significance}

- Primary criteria:

1. Historic

2. Artistic or aesthetic

3. Scientific or research potential

4. Social or spiritual

Kylie Winkworth and Roslyn Russell. Significance 2.0: a guide to assessing the significance of collections. Collections Council of Australia, 2009.

\section{Types of significance}

- Secondary criteria

1. Provenance

2. Rarity or representativeness

3. Condition or completeness

4. Interpretive capacity

Kylie Winkworth and Roslyn Russell. Significance 2.0: a guide to assessing the significance of collections. Collections Council of Australia, 2009. 


\section{But I don't have any special collections...}

- Does your organisation produce anything: newsletters, audio recordings, ephemera...

- Do you have anything that belonged to someone important? Did they make annotations?

- Is the institutional memory of your organisation being recorded?

- Do you have stuff you don't know what to do with?

- Build your own

\section{Why special collections are important}

- Enhance research - primary sources are "the raw material of history'

- Attract scholars

- Preserve unique history and memory

- Community engagement

- Promotional value

A. Flick. New York Times $5^{\text {th }}$ March 1925 


\section{Access v. preservation}

- "He... at least as I (surely unfairly) remember him, he might as well have worn a sign about his neck reading Noli me tangere (or my books, either)" "Traister (2000) p. .58.

- "On the one hand, readers need access; on the other, our materials need protection... We can ignore neither side of these pairs, yet both have the constant potential to conflict" "Irasiser (2000), p.6.6.

\section{Excursus: gloves}

- Are you: a) Mickey Mouse, b) a band leader, or c) handling rare books? If c) - leave the white cotton gloves at home

- Cotton gloves are slippery and break off the edges of pages

- Clean dry hands are fine for books and paper

- Nitrile gloves are necessary for handling photographs, glass or metal objects 


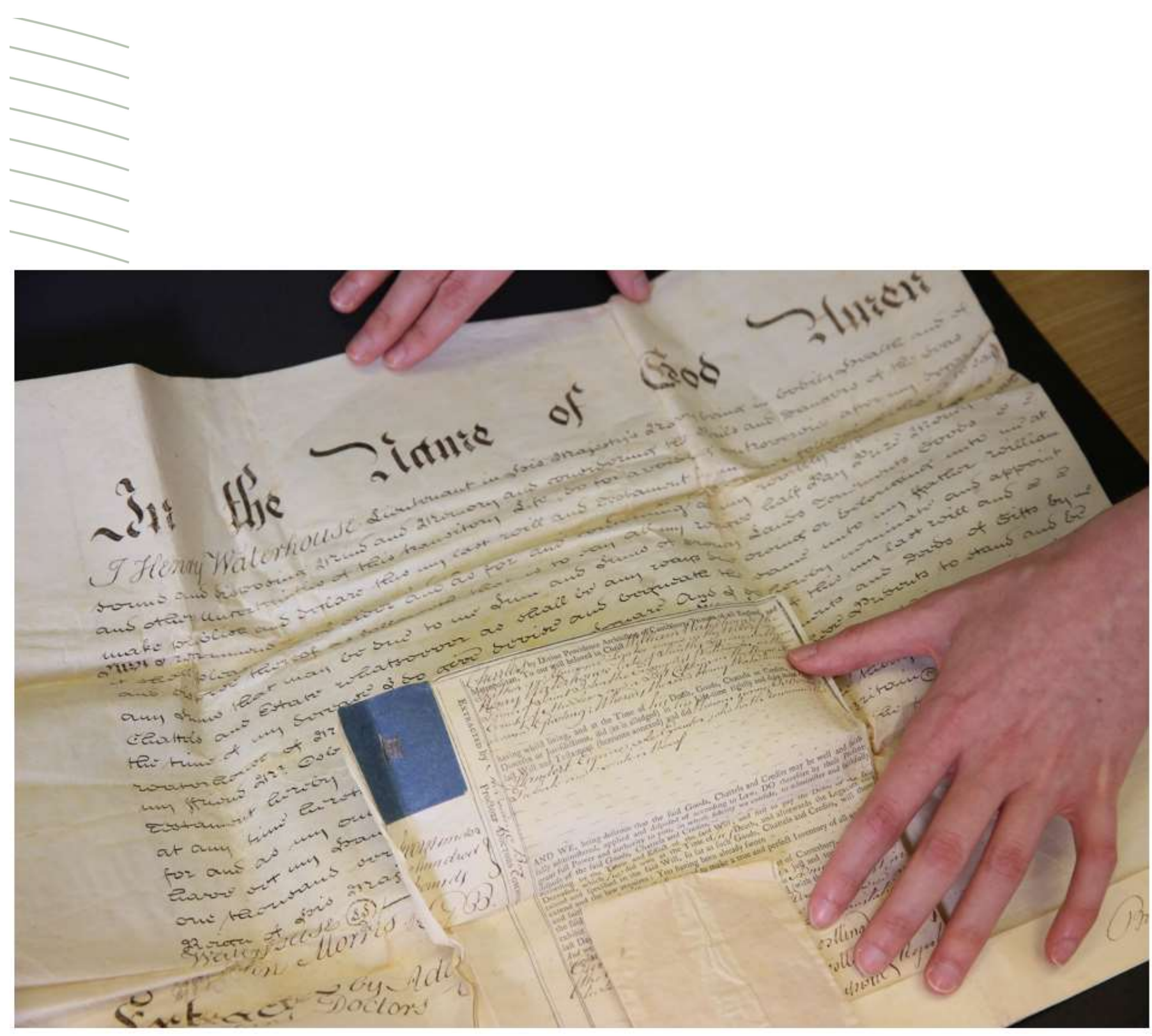

\section{Metadata for special collections}

- Published material - provenance, annotations \& features recorded in the 590 and 700 fields

- Archives management system - records, manuscripts, ephemera

- Finding aid

- Any metadata is better than none 


\begin{tabular}{|c|c|}
\hline \multirow{2}{*}{\multicolumn{2}{|c|}{$\begin{array}{l}\text { Uniform title: } \\
\text { Title: }\end{array}$}} \\
\hline & \\
\hline \multicolumn{2}{|c|}{ 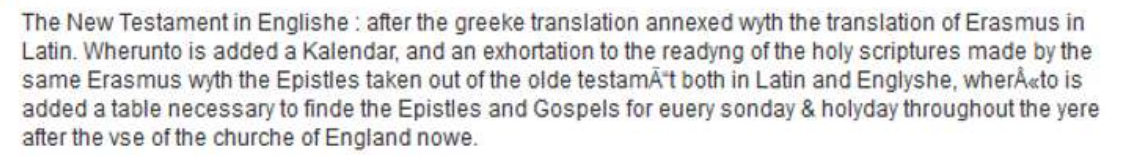 } \\
\hline Publication info: & Excusum Londini : in officina ThomÄ: Gaultier. pro I. C., 1550. \\
\hline Physical description: & [264] leaves ; 18 \& $19 \mathrm{~cm}$. (8vo) \\
\hline \multicolumn{2}{|l|}{ General Note: } \\
\hline \multicolumn{2}{|c|}{ The fourth edition of Tyndale's English version with the translation of Erasmus in Latin. } \\
\hline \multicolumn{2}{|l|}{ General Note: } \\
\hline \multicolumn{2}{|c|}{ 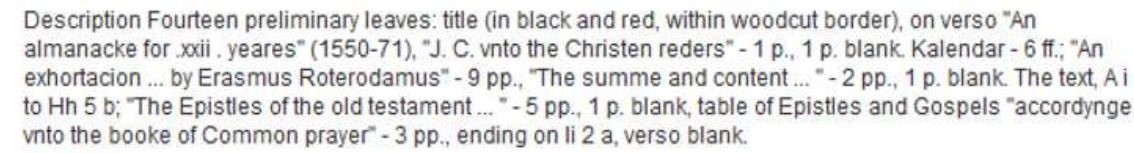 } \\
\hline \multicolumn{2}{|l|}{ General Note: } \\
\hline \multicolumn{2}{|c|}{$\begin{array}{l}\text { The initials I.C. (i.e. J.C.) stand for the name of the publisher, who, according to his preface, was also editor. } \\
\text { They may indicate John Cawood, the London printer. There appears to be no adequate reason for connecting } \\
\text { this edition with the name of Sir John Cheke. }\end{array}$} \\
\hline General Note: & Signatures: *â,, [Maltese cross]âf. A-Zâ, Aa-Hhâ, liễz. \\
\hline \multicolumn{2}{|l|}{ Local note: } \\
\hline \multicolumn{2}{|c|}{$\begin{array}{l}\text { "Black letter text. Pages not numbered. (528pp-text). Of the preliminary leaves present, only the title page and } \\
\text { Epistle to the Reader are present here, in skillful facsimile in red and black. First leaf in Matthew in similar } \\
\text { good facsimile. Possibly the final two table leaves at close also. One leaf in Mark repaired and remargined } \\
\text { outer edge. Minor marks. Some outer marginal notes shaved or very slightly trimmed in places. A very good } \\
\text { copy. 19th century red grained morrocco. Blind line borders. Ownership bookplate and signatures from } 1917 \text {. } \\
\text { Scarboro, UK. DMH } 88 \text {. The Fourth Edition of Tyndale's English New Testament, with Erasmus's Latin } \\
\text { Translation added for good measure, in parallel columns. Quite scarce nowadays, and always sought after. } \\
\text { NB. This could have come from Francis Fry's collection, though nothing positively identifies it. The excellent } \\
\text { facsimiles in red and black are very reminiscient of his productions on old paper. Also the } 19 \text { th century } \\
\text { bindings are similar to what he had done. Finally, the book has come from a source where other of Francis } \\
\text { Fry's books" - - Booksellers notes, Humber Books. }\end{array}$} \\
\hline $\begin{array}{l}\text { Added Entry-Personal } \\
\text { Name: }\end{array}$ & Tyndale, William, d. 1536. \\
\hline $\begin{array}{l}\text { Added Entry-Personal } \\
\text { Name: }\end{array}$ & Erasmus, Desiderius, d. 1536. \\
\hline
\end{tabular}

Reflections for every day in the year : on the works of God : and his providence throughout all
nature

Sturm, Christoph Christian, 1740-1786,

ocn523076243

Local system \#: $\quad$ (OCoLC)523076243

Personal Author: Sturm, Christoph Christian, 1740-1786,

Uniform title: [Betrachtungen $\tilde{A}^{1} / 4$ ber die Werke Gottes. Selections. English]

Title:

Reflections for every day in the year : on the works of God : and his providence throughout all nature / translated by John Hemet.

Publication Info:

London : Rivington, 1823.

Physical description: $\quad x v i, 403$ pages : illustrations ; $17 \mathrm{~cm}$

Local note:

Society for Promoting Christian Knowledge stamp on front cover. Inscription on fly-leaf: A small token of remembrance to Master W. Blaxland from M. Marsden June 241829.

Subject term: Devotional literature, German--Translations into English.

Subject term: $\quad$ Nature--Religious aspects--Christianity.

Subject term: Natural theology--Early works to 1800.

Subject term: Meditations--Early works to 1800.

Subject term: Devotional calendars.

Added Entry-Personal Blaxland, William,

Name: 
www.accesstomemory.org

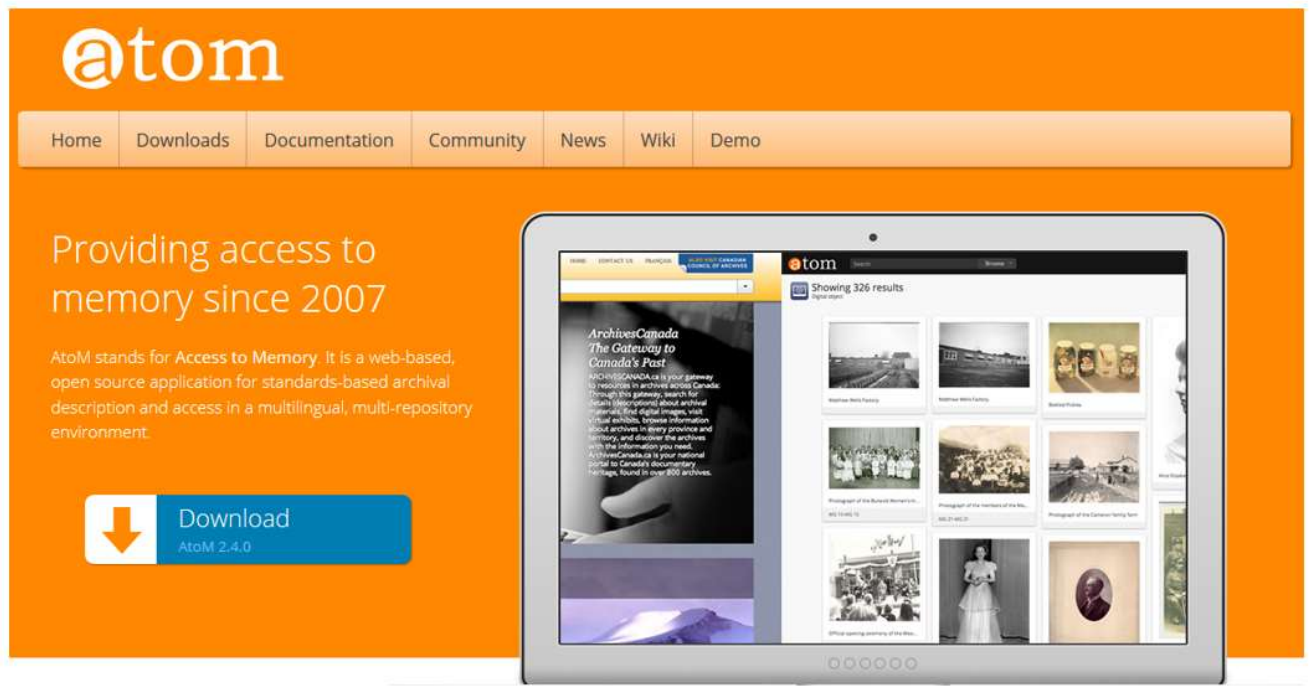

\section{Digitisation}

- Digitisation is not digital preservation

- A website is not a digital asset management system

- Metadata first, conservation second, digitisation third

\section{Digital preservation}

- "The coordinated and ongoing set of processes and activities that ensure long-term, error-free storage of digital information, with means for retrieval and interpretation, for the entire time span the information is required..."

State Library of New South Wales (2015) Digital Preservation. Retrieved from: http://www.sl.nsw.gov.au/public-library-services/digital-practice-guidelines-public-libraries/digital- 


\section{Digital preservation}

- Use sustainable file formats

- Use detailed and standardised metadata

- Replication - creation of multiple copies of data at one or more locations

- Refreshing - the transfer of data between two types of the same storage medium

- Migration - the transferring of data to a newer hardware and/or software environment

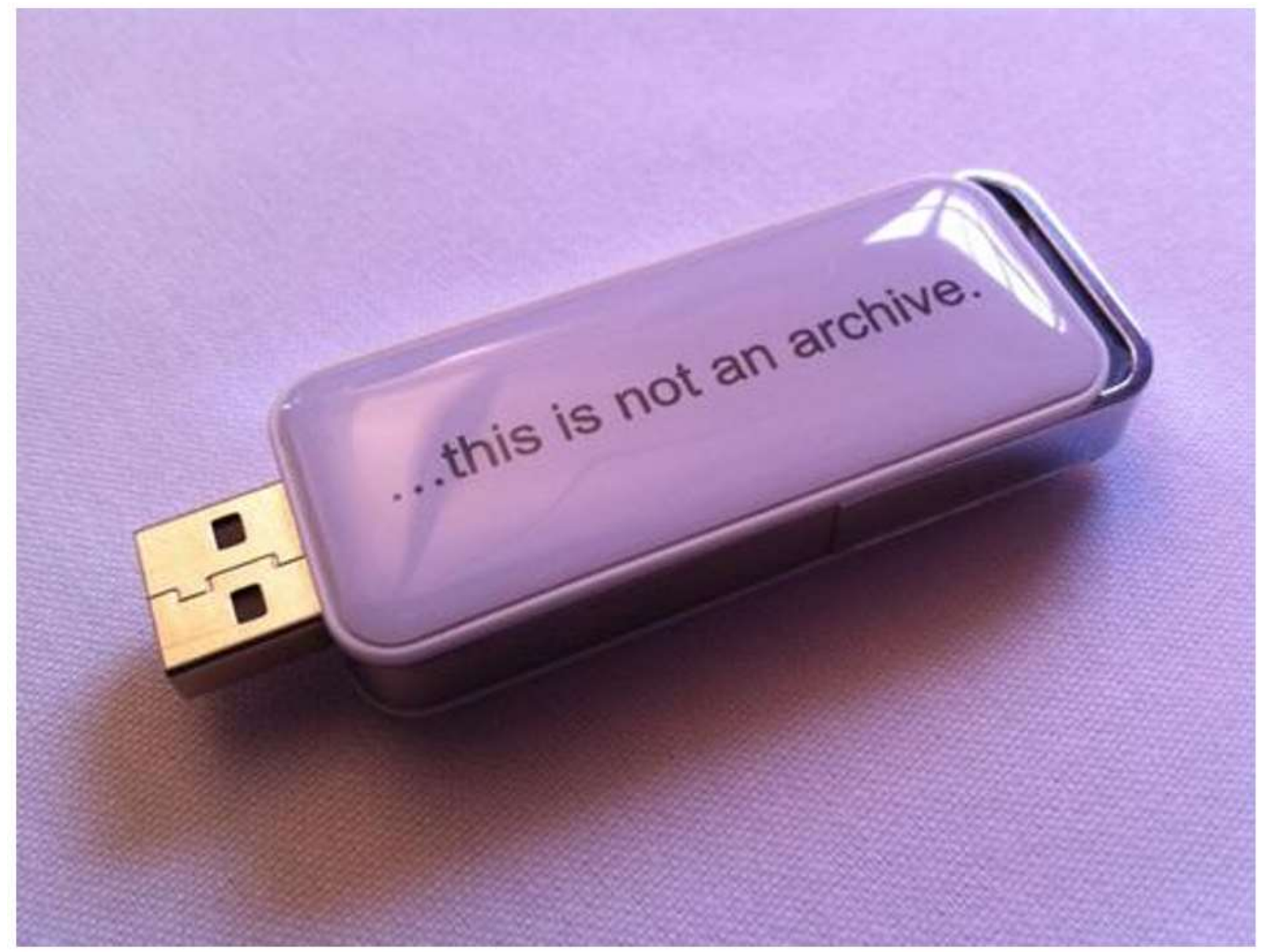

Lingel, Jessa (2013) 'This is not an archive' Retrieved from: http://jessalingel.tumblr.com/post/66108958850/this-is-not-an-archive 


\section{Digital asset management systems}

- Ex Libris Rosetta

- D-Space

- Fedora

- Archivematica

- ContentDM from OCLC

Christian voices in the public square

\begin{tabular}{|c|c|c|}
\hline dc.contributor.author & Jensen, Peter F. & \\
\hline dc.date.accessioned & 2016-10-11T07:23:05Z & \\
\hline dc.date.available & 2016-10-11T07:23:05Z & \\
\hline dc.date.issued & $2013-06-26$ & \\
\hline dc.identifier.uri & https://myrrh.library.moore edu.au. $443 /$ handle/10248/8957 & \\
\hline dc.format.extent & 01:07:51 & en_AU \\
\hline dc.title & Christian voices in the public square & en_AU \\
\hline
\end{tabular}

Files in this item

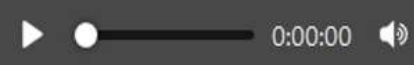

Name: Christian-Voices-in-the-Public-Squa re-PFJ.mp3

Size: $\quad 93.04 \mathrm{Mb}$

Format: $\mathrm{mp} 3$ audio 
www.digitalcollections.org.au

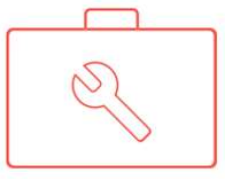

Toolkit

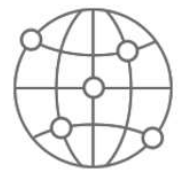

Framework

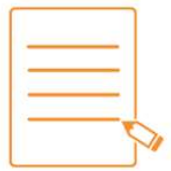

Workshops

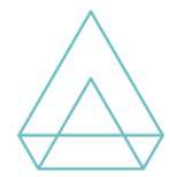

GLAM Peak

\section{Collaborative digitisation}

- Australia - become a digitisation partner with Trove

- New Zealand - National Library's Papers Past project

- The resulting files will be made available on a secure platform and will be actively preserved

昆Trove help centre

Trove Help » Becoming a partner » For digitisation partners

For digitisation partners

On this page...

Partner with us

Next steps for digitisation partners

Partner with us

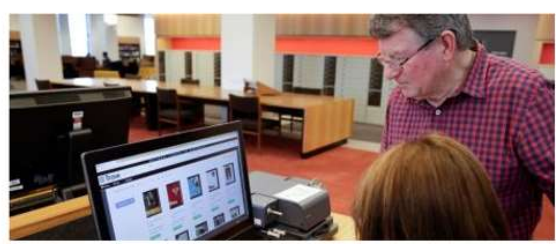

Trove Forum Contact Blog Search

\section{Trove Help}

- Using Trove

- Becoming a partner

For digitisation partners

- Digitisation partner guidelines

- Guidelines for journal digitisation

- Guidelines for hardcopy newspapers digitisation

- Digitisation case studies

- Digitisation workflow process overview

- Optical Character Recognition (OCR) on 

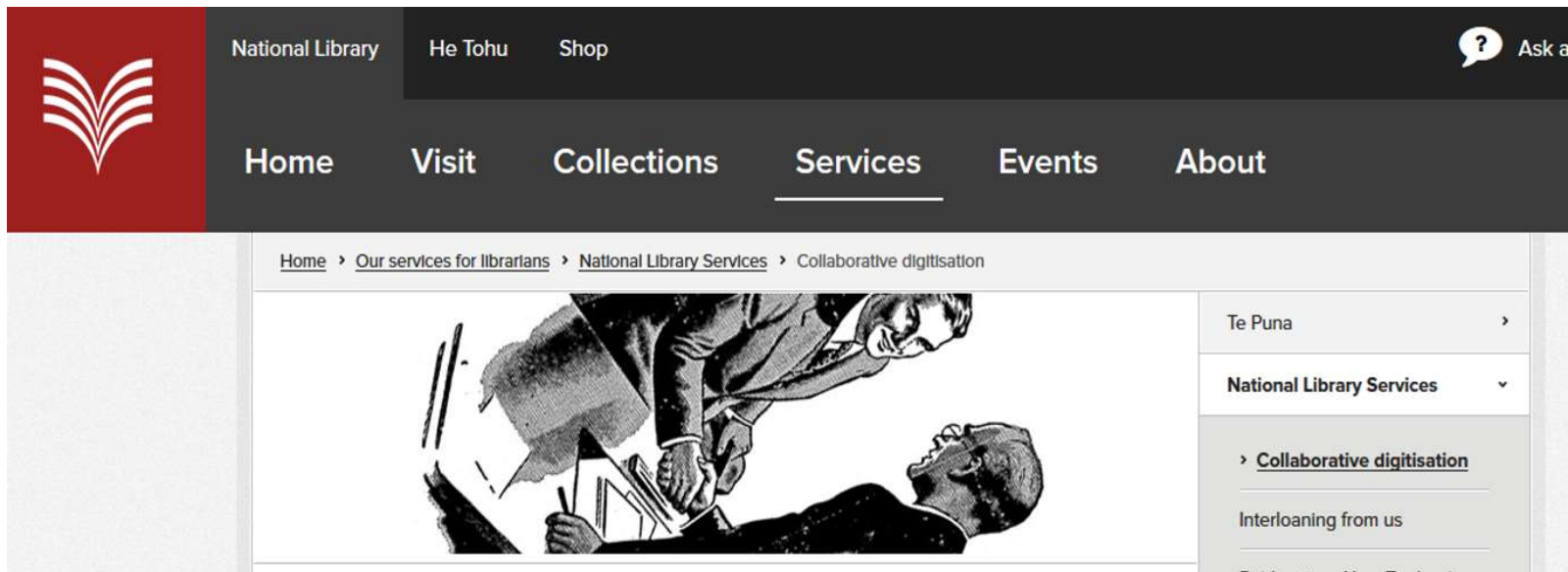

\section{Collaborative digitisation}

Every year we invite community groups to collaborate with us in adding more newspapers to Papers Past. $匚$ You can apply to be part of this programme if you have a newspaper title you want to digitise and add to Papers Past. We'll get it online and split the costs with you, 50/50.

Te Puna

National Library Services

> Collaborative digitisation

Interloaning from us

Publications New Zealand

Cataloguing

Levels of cataloguing

Directory of New Zealand

The 2018/2019 programme

Applications for the 2018/19 programme have now closed.

\section{"special"?}

- Special collections are an asset to an institution and its researchers

- Managing them requires creativity and branching out into other GLAM domains

- Explore available programs and resources

- DIGITISATION IS NOT DIGITAL PRESERVATION

\section{Questions?}

